\title{
Developments in autonomic research: a review of the latest literature
}

\author{
Vaughan G. Macefield
}

Published online: 11 July 2009

(C) Springer-Verlag 2009

\begin{abstract}
Small-diameter afferents do not just subserve pain and temperature sensibilities, important for protection of the body though they are: there is a system of lowthreshold unmyelinated afferents that respond to light stroking (C-tactile afferents) and they are believed to subserve the affective components of touch. Patients with large-fibre sensory neuropathies exhibit skin sympathetic responses to stroking, and report the stimuli as feeling pleasant. Moreover, the posterior insula is activated. Patients with small-diameter sensory neuropathies, specifically those with congenital insensitivity to pain, suffer from cumulative injuries that can lead to joint degeneration. There is evidence that the nociceptive (and sympathetic) axons die because nerve growth factor is not being produced by the target tissues; patients with congenital insensitivity to pain have mutations in the NTRK1 gene, the gene responsible for producing the TrkA receptor, but there is also evidence for mutations in the SCN9A gene, which codes for a specific subunit of the voltage-gated sodium channel. Specific mutations, leading to clusters of cases of congenital insensitivity to pain, have been found in several geographical locations, with several genetic mutations having been documented. Interestingly, even patients with congenital insensitivity to pain, despite having never experienced pain, can still empathise with the pain in others-we do not need to feel pain in order to empathise, but we do need to feel pain in order to ensure that our body looks after itself.
\end{abstract}

V. G. Macefield ( $₫)$

School of Medicine, University of Western Sydney, Locked Bag 1797, Penrith South DC, NSW 1797, Australia

e-mail: v.macefield@uws.edu.au
Keywords Congenital insensitivity to pain . Genetic clusters - HSAN - Nerve growth factor . Neuropathy $\cdot$ NTRK1 gene $\cdot$ SCN9A gene . Unmyelinated afferents · Unmyelinated efferents

\section{That touchy feeling}

Neuropathies of large-diameter myelinated afferents are rare, and usually follow a viral infection. While motor axons are not affected, motor function is disturbed through loss of the sensory input from the skin and muscles that is essential for sensorimotor coordination. People with this disorder typically have to rely on vision in order to perform skilled movements with their hands, for example. What are preserved are the small-diameter axons-the unmyelinated afferents and efferents: subjects can still perceive temperature and noxious stimuli, and they possess normal autonomic function. Nociceptive and thermosensitive afferents are important in protecting the body from injury. In addition, people with loss of large-diameter afferents still possess low-threshold mechanosensitive afferents, the C-tactile fibres. These unmyelinated afferents, present only in hairy skin, are sensitive to light stroking of the skin. First characterised in detail in 1993 by Vallbo, Olausson, Wessberg and Norsell from the Institute of Neuroscience and Physiology, Göteborg University, Sweden [19], and reviewed by this group in an upcoming issue of Neuroscience and Biobehavioural Reviews [13], these authors suggested that $\mathrm{C}$-tactile fibres subserve an affective component of touch, engaging areas of the brain involved in the processing of emotion rather than those comprising the discriminative somatosensory system. Indeed, studies in two patients lacking large-fibre sensory axons yet preserved small-fibre function reveal that their capacity to feel 
this light touch remains. Moreover, the stroking stimuli feel "pleasant" and, as described by Olausson and colleagues in the May 2008 issue of Neuroscience Letters, functional magnetic resonance imaging (fMRI) studies have shown that light stroking of the hairy skin in these patients activates the posterior insular cortex but not the primary somatosensory cortex [12]. The contribution of C-tactile fibres to affective touch has been further explored by Löken and colleagues, in the May issue of Nature Neuroscience [9]. The authors show that, while large-diameter cutaneous afferents preferentially respond to brisk brush strokes, C-tactile afferents respond preferentially to slow rates of stroking-just the kind we (and cats) like. What has this to do with the autonomic nervous system, I hear you ask? Well, as described by Olausson and colleagues in the January 2008 issue of Experimental Brain Research, activation of $\mathrm{C}$-tactile afferents evokes a sympathetic skin response (i.e. sweat release) — consistent with the idea that these low-threshold unmyelinated afferents are involved in the affective aspects of touch [11].

\section{A life without pain}

As noted above, patients with large-fibre sensory neuropathy can still feel noxious stimuli, but what of those patients with a disorder that affects the small-diameter axons? Congenital insensitivity to pain is part of a spectrum of hereditary sensory and autonomic neuropathies (HSANs) that encompass a number of inherited disorders associated with sensory dysfunction (e.g. altered pain and temperature perception) and differing degrees of autonomic dysfunction (gastroesophageal reflux, postural hypotension, excessive sweating). So far, they have been divided into five types according to the different patterns of expression of sensory and autonomic dysfunction, peripheral neuropathy, clinical features, and genetic abnormalities. As with the small-fibre neuropathies produced by diabetes and leprosy, congenital insensitivity to pain affects the body's capacity to protect itself against tissue damage and predisposes the patient to an increased incidence of traumatic injuries. Even small, apparently inconsequential injuries can accumulate and lead to serious complications. One such complication is joint degeneration, and the consequent loss of joint stability. In the April 2007 issue of Strategies in Trauma and Limb Reconstruction, Verheyen and colleagues, from the Department of Orthopaedic Surgery and Traumatology at the de Weezenlanden Hospital in Zwolle, The Netherlands, report on the case of a young boy who suffered a series of minor injuries that ultimately led to collapse and dislocation of both hips [20]. While most of these problems manifest in childhood, Cassidy and Schaffer, from the University of Kentucky Medical Center in
Lexington, Kentucky, USA, report in the July 2008 issue of Spine Journal on the severe neuropathic (Charcot) arthropathy evident in an adult patient that led to collapse of the spinal column, ultimately requiring anterior and posterior vertebral fixation [3]. A retrospective review of nearly 600 paediatric patients, performed by Feldman and colleagues at the Division of Pediatric Orthopaedic Surgery in the New York University Hospital for Joint Diseases, USA, is reported in the January 2009 issue of the Journal of Pediatric Orthopedics [7]. The authors compared patients with two types of HSAN, and showed that type IV was most commonly associated with Charcot arthropathy. Oral problems can also occur with these neuropathies: Singla and colleagues, from the Department of Pedodontics and Preventive Dentistry at the Government Dental College in Haryana, India, describe in the May 2008 issue of the Journal of Dentistry in Childhood the case of a young boy with multiple missing teeth and a habit of self-mutilation [16]. And in the January 2009 issue of the Journal of Oral Rehabilitation, Paduano and colleagues, of the Department of Dental, Oral and Maxillo-Facial Sciences at the University of Catanzaro Magna Graecia, Italy, report on a young boy who developed oral lesions from biting the inside of his cheeks, which led to him having to wear a mouthguard [14]. Some of the complications referred to above may well reflect disturbances in sympathetic innervation of, for example, the joints, and emphasise the role of the autonomic nervous system in ongoing regulation of a tissue's microenvironment. Indeed, in the May 2009 issue of Autonomic Neuroscience, Indo, from the Department of Pediatrics at Kumamoto University Hospital in Kumamoto, Japan, comments on the lack of nerve growth factor (NGF) in patients with congenital insensitivity to pain [8]. NGF is a neurotrophic factor that is essential for the survival and maintenance of both unmyelinated sensory and sympathetic neurones: patients with congenital insensitivity to pain with anhidrosis (CIPA) have loss-of-function mutations in the NTRK1 gene (chromosome 1) that encodes TrkA, a receptor tyrosine kinase for NGF [8]. Accordingly, loss of NGF production in the target tissues will result in loss of afferent and efferent neurones.

\section{Genetic clusters}

In the October 2007 issue of the Orphanet Journal of Rare Diseases, Axelrod and colleagues, from the Department of Pediatrics at New York University School of Medicine, New York, USA, review the HSANs, focussing on those variants that have been most studied (types II-IV). These are characterised by autosomal recessive inheritance and onset at birth [1]. HSANs affect both males and females. One of the best known of these is familial dysautonomia 
(Riley-Day syndrome or HSAN III), which is often used as a prototype for comparison to the other HSAN; HSAN III is almost exclusively limited to people of Eastern European Jewish origin. It is likely that each variant of HSAN is caused by different genetic errors that determine the phenotype. In the December 2007 issue of the Journal of Orthopedic Surgery, Shalimar and colleagues, from the Department of Orthopaedics and Traumatology in the Faculty of Medicine at Universiti Kebangsaan Malaysia, describe a Malaysian family with congenital insensitivity to pain with anhydrosis, members of which suffered from chronic ulcers, joint deformities, malunited fractures, anhydrosis, and learning disabilities [15]. The authors detected a compound heterozygous mutation in exon 16: V709L from the mother and G718S from the father. Two novel mutations were also identified: at amino acid 709, a change of $\mathrm{G}$ to $\mathrm{C}$ at nucleotide 2209 causing a valine to leucine substitution, and at amino acid 718, a change of $\mathrm{G}$ to $\mathrm{A}$ at nucleotide 2236 causing a glycine to serine substitution. Such simple genetic errors, yet such profound consequences. Another cluster was found in Turkey, this time affecting NTRK1, the gene that encodes for the receptor for NGF: in the May 2008 issue of Neurogenetics, Tüysüz and colleagues, from the Department of Pediatrics at the Istanbul University Cerrahpasa Faculty of Medicine, Turkey, identified six families from Northern Central Turkey with HSAN IV [18]. The authors screened for mutations in the NTRK1 gene and revealed one novel frameshift mutation, two novel nonsense mutations, and three unrelated types with the same splice-site mutation; genotyping of the three families with the identical splice-site mutation showed that they share the same haplotype, suggesting that a specific mutation developed in Turkey. Similar mutations have been found in Morocco: in the March 2009 issue of Clinical Genetics, Suriu and colleagues, from the Institute of Human Genetics at the Western Galilee Hospital-Nahariya, Israel, identified an identical novel nonsense mutation in two unrelated families of Moroccan Jewish descent, each with two affected siblings [17]. The authors reason that the founder mutation may be traced to the rural Jewish village in southern Morocco from where both these families originated. There is also a cluster of people with congenital insensitivity to pain in the far north of Sweden: in an upcoming issue of Neuroscience [2], Axellson and colleagues, from the Department of Laboratory Medicine at Lund University Hospital, Sweden, show that forearm skin biopsies taken from people with Norrbottnian congenital insensitivity to pain have essentially no sensory C-fibres that express the transient receptor potential (TRP) receptors-TRP vanilloid receptor type 1 (TRPV1), vanilloid 2 (TRPV2) and melastatin 8 (TRPM8). Finally, Nilsen and colleagues, from the Department of Neuroscience at the Norwegian University of Science and Technology in
Trondheim, Norway, report in the May 2009 issue of Pain a woman with insensitivity to pain in whom two novel mutations in the SCN9A gene, which codes for a specific subunit of the voltage-gated sodium channel $\mathrm{Na}(\mathrm{v}) 1.7$, were found [10]. Indeed, as described by Drenth and Waxman, of the Department of Medicine at the University Medical Center St. Radboud in Nijmegen, The Netherlands, in the December 2007 issue of the Journal of Clinical Investigation, disorders in the SCN9A gene have important consequences for the processing of nociceptive information: while nonsense mutations in $\mathrm{Na}(\mathrm{v}) 1.7$ result in insensitivity to pain, gain-of-function missense mutations in $\mathrm{Na}(\mathrm{v})$ 1.7 have been shown to cause paroxysmal extreme pain disorder [6].

\section{I feel your pain}

If you have never experienced pain yourself, can you still understand its significance in others? Interestingly, the answer is yes, according to Danziger and colleagues, from the Département de Neurophysiologie at the Faculté de Médecine Pitié-Salpêtrière in Paris, France. In the September 2006 issue of Brain, these investigators showed that ratings of verbally presented imaginary painful situations were not different between people with congenital insensitivity to pain and control subjects. Likewise, there was no difference between the two groups in inferring pain from facial expressions, suggesting that personal experience of pain is not necessarily required to perceive-and feel empathy for-pain in others [5]. Interestingly, a recent fMRI study, conducted by the same group and reported in the January 2009 issue of Neuron, demonstrated that patients with congenital insensitivity to pain showed normal fMRI responses to observed pain in the anterior midcingulate cortex and anterior insula-regions which are activated in normal subjects when they experience real pain, or when they observe pain being administered to others [4]. So, we do not need to have experienced physical pain to be able to empathise with others, but we do need to feel pain in order to ensure that our body looks after itself.

\section{References}

1. Axelrod FB, Gold-von Simson G (2007) Hereditary sensory and autonomic neuropathies: types II, III, and IV. Orphanet J Rare Dis 2:39

2. Axelsson HE, Minde JK, Sonesson A, Toolanen G, Högestätt ED, Zygmunt PM (2009) TRPV1, TRPV2 and TRPM8 immunoreactive nerve fibres in human skin from individuals with and without Norrbottnian congenital insensitivity to pain. Neuroscience [Epub ahead of print] 
3. Cassidy RC, Shaffer WO (2008) Charcot arthropathy because of congenital insensitivity to pain in an adult. Spine J 8:691-695

4. Danziger N, Faillenot I, Peyron R (2009) Can we share a pain we never felt? Neural correlates of empathy in patients with congenital insensitivity to pain. Neuron 61:203-212

5. Danziger N, Prkachin KM, Willer JC (2006) Is pain the price of empathy? The perception of others' pain in patients with congenital insensitivity to pain. Brain 129:2494-2507

6. Drenth JP, Waxman SG (2007) Mutations in sodium-channel gene SCN9A cause a spectrum of human genetic pain disorders. J Clin Invest 117:3603-3609

7. Feldman DS, Ruchelsman DE, Spencer DB, Straight JJ, Schweitzer ME, Axelrod FB (2009) Peripheral arthropathy in hereditary sensory and autonomic neuropathy types III and IV. J Pediatr Orthop 29:91-97

8. Indo Y (2009) Nerve growth factor, interoception, and sympathetic neuron: lesson from congenital insensitivity to pain with anhydrosis. Auton Neurosci 147:3-8

9. Löken LS, Wessberg J, Morrison I, McGlone F, Olausson H (2009) Coding of pleasant touch by unmyelinated tactile afferents in humans. Nat Neurosci 12:547-548

10. Nilsen KB, Nicholas AK, Woods CG, Mellgren SI, Nebuchennykh M, Aasly J (2009) Two novel SCN9A mutations causing insensitivity to pain. Pain 143:155-158

11. Olausson H, Cole J, Rylander K, McGlone F, Lamarre Y, Wallin BG, Krämer H, Wessberg J, Elam M, Bushnell MC, Vallbo A (2008) Functional role of unmyelinated tactile afferents in human hairy skin: sympathetic response and perceptual localization. Exp Brain Res 184:135-140

12. Olausson HW, Cole J, Vallbo A, McGlone F, Elam M, Krämer HH, Rylander K, Wessberg J, Bushnell MC (2008) Unmyelinated tactile afferents have opposite effects on insular and somatosensory cortical processing. Neurosci Lett 436:128-132

13. Olausson H, Wessberg J, Morrison I, McGlone F, Vallbo A (2008) The neurophysiology of unmyelinated tactile afferents. Neurosci Biobehav Rev [Epub ahead of print]

14. Paduano S, Iodice G, Farella M, Silva R, Michelotti A (2009) Orthodontic treatment and management of limited mouth opening and oral lesions in a patient with congenital insensitivity to pain: case report. J Oral Rehabil 36:71-78

15. Shalimar A, Sharaf I, Farah Wahida I, Ruszymah BH (2007) Congenital insensitivity to pain with anhydrosis in a Malaysian family: a genetic analysis. J Orthop Surg (Hong Kong) 15:357-360

16. Singla S, Marwah N, Dutta S (2008) Congenital insensitivity to pain (hereditary sensory and autonomic neuropathy type V): a rare case report. J Dent Child (Chic) 75:207-211

17. Suriu C, Khayat M, Weiler M, Kfir N, Cohen C, Zinger A, Aslanidis C, Schmitz G, Falik-Zaccai TC (2009) Skoura-a genetic island for congenital insensitivity to pain and anhidrosis among Moroccan Jews, as determined by a novel mutation in the NTRK1 gene. Clin Genet 75:230-236

18. Tüysüz B, Bayrakli F, DiLuna ML, Bilguvar K, Bayri Y, Yalcinkaya C, Bursali A, Ozdamar E, Korkmaz B, Mason CE, Ozturk AK, Lifton RP, State MW, Gunel M (2008) Novel NTRK1 mutations cause hereditary sensory and autonomic neuropathy type IV: demonstration of a founder mutation in the Turkish population. Neurogenetics 9:119-125

19. Vallbo ÅB, Olausson H, Wessberg J, Norrsell U (1993) A system of unmyelinated afferents for innocuous mechanoreception in the human skin. Brain Res 628:301-304

20. Verheyen CC, Castelein RM (2007) A life without pain: a case report. Strat Trauma Limb Reconstr 2:55-56 